References

1. Blomquist, C. A hospital survey of hypocalcemia in patients with malignant disease. Acta Med Scand 1986, 220: 167-173.

2. Shills, M.E. Experimental human magnesium depletion. Medicine 1969, 118: 61-85.

3. Goddard, C., Mbauu, A. \& Evanson, J. Symptomatic hypocalcemia associated with metastatic invasion of the parathyroid glands. Br J Hosp Med 1990, 43: 72.

4. Whang, R., Oei, T.O., Aikawa, J.K., Watanabe, A. \& Vannatta, J. Predictors of clinical hypomagnesaemia, hypokalaemia, hypophosphataemia, hyponatraemia and hypocalcaemia. Arch Int Med 1984, 144: 1794-1796.

5. Kingston, M.E., Al-Sibai, M.B. \& Skooge, W.C. Clinical manifestations of hypomagnesaemia. Crit Care Med 1986, 14: $950-954$.

6. Quamme, G. Renal handling of magnesium: drug and hormone interactions. Magnesium 1986, 5: 248-272.

7. Massry, S.G. Hypomagnesaemia and hypermagnesaemia. In: Suki, W.N. \& Massry, S.G. (eds): Therapy of Renal Diseases. Martinus Nijhoff, Massachusetts, 1984, pp. 101-105.

8. Cronin, R. \& Knochel, J. Magnesium deficiency. Adv Int Med 1983, 28: 509-533.

9. Clark, A. Glucose homeostasis. In: Jung, R.T. \& Sikora, K. (eds) Endocrine Problems in Cancer. Heinemann, London, 1984, pp. $71-88$.
10. Maguire, P.J. \& MacDonald, J.S. Hypocalcaemia associated with a calcitonin producing hepatocellular carcinoma. Arch Int Med 1981, 141: 687-688.

11. Graber, M.L. \& Schulman, G. Hypomagnesaemic hypocalcaemia. Independent of parathyroid hormone. Ann Intern Med 1986, 104: 808-815.

12. Jacob, A.I., Pennell, J.P., Lambert, P.W. \& Gavellas, G. Vitamin D metabolites and parathyroid hormone in hypomagnesaemic hypocalcaemia. Min Electrolyte Metab 1981, 6: 316-322.

13. Fuss, M. Cogan, E., Gillet, C. et al. Magnesium administration reverses the hypocalcaemia secondary to hypomagnesaemia despite low circulating levels of 25-hydroxy vitamin D and 1,25-dihydroxy vitamin D. Clin Endocrinol 1985, 22: 807-815.

14. Rude, R.K. \& Singer, F.R. Magnesium deficiency and excess. Ann Rev Med 1981, 32: 245-259.

15. Tommaso, C.L. \& Tucci, J.R. Metabolic studies in a case of hypocalcaemia and osteoblastic metastases. Arch Int Med 1981, 139: 238-241.

16. Kukreja, S.C., Shunmugam, A. \& Lad, T.E. Hypocalcaemia in patients with prostate carcinoma. Calcif Tissue Int 1988 , 43: $340-345$.

\title{
Primary lymphoma of the gallbladder
}

\author{
E.P. Friedman, E. Lazda, D. Grant and J. Davis
}

Department of Imaging and Histopathology Department, The Whittington Hospital, Highgate Hill, London N19 5NF, UK

\begin{abstract}
Summary: A case of primary lymphoma of the gallbladder is described which is rare in the medical literature. A 76 year old man presented with acute cholecystitis and septicaemia. Investigation showed a lung abscess and a gallbladder mass. The mass was thought to be an empyema and cholecystostomy was performed. Biopsy of the gallbladder wall showed high-grade B cell lymphoma. The patient unfortunately succumbed to overwhelming septicaemia in the postoperative period. Postmortem examination confirmed primary lymphoma of the gallbladder without dissemination.
\end{abstract}

\section{Introduction}

Although lymphomas are thought to be primarily tumours of lymph nodes, a substantial proportion arise from other tissues. The percentage of nonHodgkin's lymphoma originating extranodally varies amongst published series from $24 \%^{1}$ to $46 \% .^{2}$ In one series of 580 patients with nonHodgkin's lymphoma $41 \%$ had primary extranodal lymphoma of which $36 \%$ arose in the gastrointestinal tract. ${ }^{3}$ Whilst a few cases have been described of primary extranodal lymphoma origi-

Correspondence: E. Friedman, M.R.C.P.

Accepted: 30 November 1992 nating in the pancreas and liver, ${ }^{4}$ the gallbladder as the site of origin is extremely rare. Lymphomatous involvement of the wall of the bile ducts has been described $^{5}$ as well as two cases of extranodal lymphoma originating in the extrahepatic bile ducts. Cholecystitis is a rare presenting feature of lymphoma.

\section{Case report}

A 76 year old man presented with a 6 week history of malaise, weight loss, right upper quadrant pain 
and shortness of breath. On examination he was pyrexial pulse 90 , blood pressure $90 / 60 \mathrm{mmHg}$ and had a tender right upper quadrant mass. There was no lymphadenopathy or splenomegaly.

A chest X-ray showed consolidation and a fluid level in the right lower lobe. Ultrasound of the abdomen showed an $11 \times 6 \mathrm{~cm}$ hypoechoic, solid mass in the region of the gallbladder fossa which contained gas and calcification. The ultrasound differential diagnosis was a carcinoma of the proximal transverse colon with possible invasion into the right lobe of the liver or a gallbladder carcinoma.

A computed tomographic (CT) scan of the lower chest showed a large, rounded area of consolidation in the right lower lobe containing gas which had the features of a lung abscess; a CT scan of the abdomen (Figure 1) showed a low density, $5 \times 6 \mathrm{~cm}$ soft tissue mass in the gallbladder fossa displacing the contrast-filled second part of the duodenum laterally. The mass contained a large calculus and air. There was abnormal tissue extending into the left lobe of the liver superiorly and into the omentum inferiorly. There was no focal liver pathology nor lymphadenopathy. The lung abscess and gallbladder mass did not appear to communicate as there was no subphrenic collection.

The probable diagnosis was changed to empyema of the gallbladder following acute cholecystitis, with a lung abscess secondary to septicaemia.

A cholecystostomy was performed through a right subcostal incision. The omentum was inflamed and adherent to the liver and gallbladder. The necrotic fundus of the gallbladder was opened revealing a small amount of thin pus and two large gallstones. A Foley catheter was left in situ. There was no subphrenic collection.

The surgical specimen consisted of a piece of grey tissue $6 \times 4 \times 0.8 \mathrm{~cm}$. Histology showed (Figure 2)

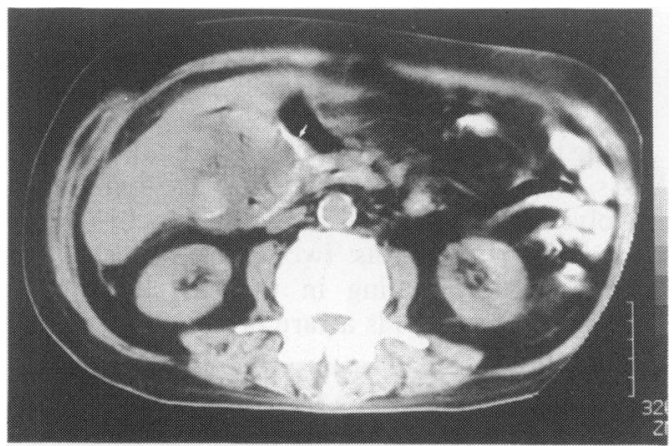

Figure 1 Contrast enhanced CT through the upper abdomen showing a gallbladder mass containing calculi and air which is displacing the contrast-filled duodenum (arrow) and merges with the right lobe of the liver.

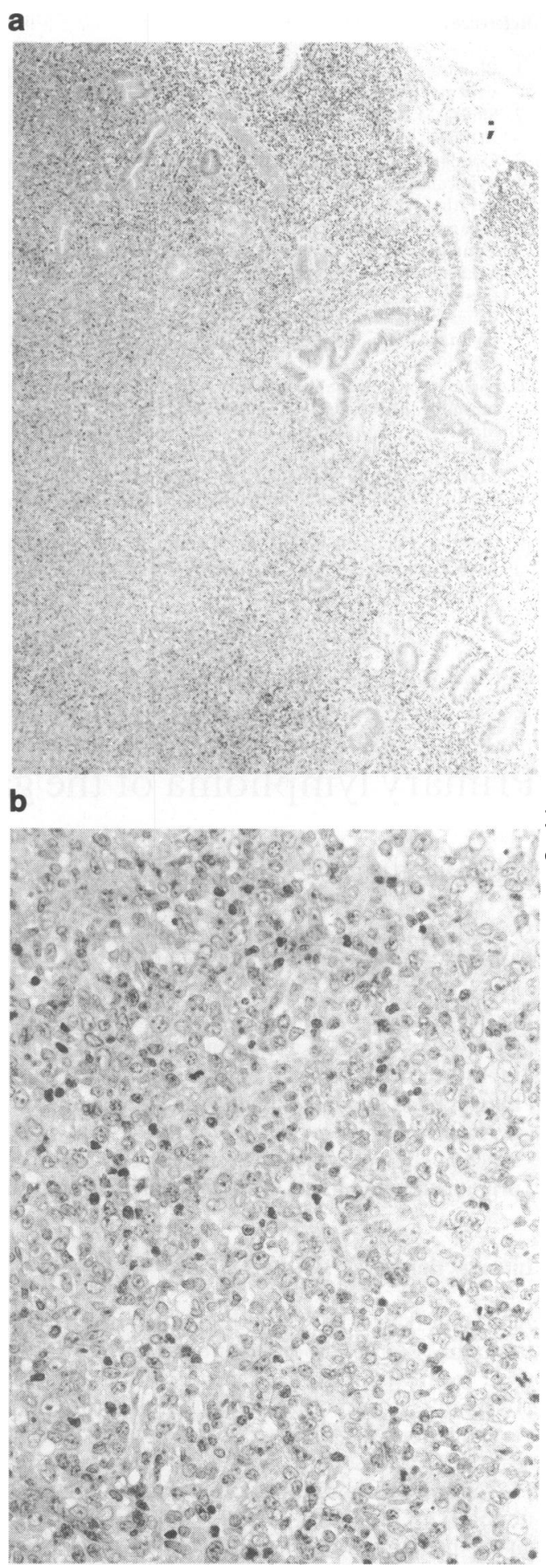

Figure 2 Photomicrographs of surgical specimen. (a) infiltration of the gallbladder mucosa by neoplastic infiltrate, and (b) high power view showing high-grade lymphoma. 
a gallbladder wall with an extensive infiltrate of large lymphoid cells with pleomorphic nuclei and frequent mitoses. Areas of haemorrhage and necrosis were present. Immunohistochemistry showed the infiltrate to be composed of B-lymphocytes showing Kappa light chain restriction. A diagnosis of high-grade B-cell lymphoma was made.

The patient died postoperatively from septicaemia. At autopsy, an $8 \mathrm{~cm}$ cavitating mass was found in the region of the gallbladder, which was extending into the liver. The histological appearance of this mass was the same as that of the surgical specimen. The remainder of the lymphoreticular system was macroscopically normal, with no evidence of lymphoma. There was also a $6 \mathrm{~cm}$ abscess in the lower lobe of the right lung which was adherent to the diaphragm. A diagnosis of primary lymphoma of the gallbladder was made.

\section{Discussion}

This case is of interest for a number of reasons. It illustrates the difficulty of diagnosis of primary extranodal lymphoma and is a case of a rare condition presenting as a common clinical situation in which reaching the correct diagnosis carries important therapeutic implications.

Extranodal lymphomas are those arising from tissues other than recognized lymphoid organs and being confined to the primary site at presentation (stage I) or the primary site and contiguous lymph nodes (stage II). Most extranodal lymphomas occur in the gastrointestinal tract but other common sites are skin, orbit, lung, thyroid and salivary glands. Less common are brain, bone, gonads, breast and soft tissues. ${ }^{6}$

\section{References}

1. Freeman, C., Berg, J.W. \& Cutler, S.J. Occurrence and prognosis of extranodal lymphomas. Cancer 1972, 29: $252-260$

2. Sarpal, S.C., Paydas, S., Tuncer, I. et al. Non-Hodgkin's lymphoma in Turkey. Cancer 1988, 62: 1653-1657.

3. Otter, R., Gerrits, W.B., Sandt, M.M. et al. Primary extranodal and nodal non-Hodgkin's lymphoma. A survey of a population-based registry. Eur J Cancer Clin Oncol 1989, 25: $1203-1210$.

4. Anthony, P.P. Primary lymphoma of the liver. J Clin Pathol 1990, 143: 1007.

5. Tartar, V.M. \& Balfe, D.M. Lymphoma in the wall of the bile ducts: radiologic imaging. Gastrointestinal Radiol 1990, 15: 53-57.

6. Isaacson, P.G. Extranodal lymphoma. In: McGee, J.O'D., Isaacson, P.G. \& Wright, N.A. (eds). Oxford Textbook of Pathology. Oxford University Press, Oxford, 1992, Vol 2b, p. 1787.
Primary lymphoma arising in the liver is well recognized and more than 50 cases have been reported in the literature. ${ }^{4}$ Primary lymphoma of the extrahepatic bile ducts is extremely rare. Nguyen ${ }^{7}$ reported one case where a biopsy from the common bile duct from a patient clinically presenting with sclerosing cholangitis, showed lymphomatous infiltration which was subsequently confirmed to be lymphoma on biopsy of a lymph node after dissemination had occurred.

Malignant lymphoma involving the gallbladder as a feature of widespread dissemination was found in 30 of 1,269 cases of 'lymphosarcoma' ${ }^{8}$ Primary lymphoma by contrast is extremely rare. A lymphoma of mucosa-associated lymphoid tissue (MALT), arising in the gallbladder has been reported recently. ${ }^{9}$

Acute or chronic cholecystitis as the presenting feature of lymphoma is rare. A case reported by Tishler ${ }^{10}$ describes disseminated lymphoma presenting as acute acalculous cholecystitis. On ultrasound the gallbladder had a thick, oedematous wall.

The clinical features in this case strongly suggested an infective focus. The presence of the solid mass on ultrasound is not a typical feature of empyema and suggests the possibility of associated malignancy. Lymphoma should be added to the differential diagnosis of a gallbladder mass in addition to carcinoma and metastases.

\section{Acknowledgement}

We would like to thank Professor Whyllie for allowing us to report this case.

7. Nguyen, G. Primary extranodal non-Hodgkin's lymphoma of the extrahepatic bile ducts. Cancer 1982, 50: 2218-2222.

8. Rosenburg, S.A., Diamond, H.D., Jaslowitz, B. \& Craver, L.F. Lymphosarcoma: a review of 1269 cases. Medicine 1961, 40: $31-84$

9. Mosnier, J.F., Brousse, N., Sevestre, C. et al. Primary low grade lymphoma of the mucosa associated lymphoid tissue arising in the gallbladder. Histopathology 1992, 20: 273-275.

10. Tishler, M., Rahmani, R., Shilo, R., Armon, S. \& Abramov, A.L. Large cell lymphoma presenting as acute choleycystitis. Acta Haematol 1987, 77: 51-52. 